\title{
Analysis and Prediction of Risks From Rockfall in the Huancavelica City
}

Iván Ayala Bizarro, Victor Paitan Sedano, Edman Ventura Sullca, Marco Lopez Barrantes, Hugo Lujan Jeri, Abdon Olivera Quintanilla, Jorge Ortega Vargas and Carlos Gaspar Paco

Department of Civil Engineering, National University of Huancavelica, Huancavelica 09001, Peru

\begin{abstract}
This research refers to the analysis and prediction of rockfall risk, whose objective is to determine the results of the validation of the model and application of modeling in the Rocfall Software, in this way to prepare the map of risk areas. Likewise, the general problem was identified: What are the results of the analysis and prediction of risks from rockfall in the city of Huancavelica? To respond to the problem posed, the following steps were carried out: obtaining field information with Drone equipment and using photogrammetric processes the topography of the study area was obtained, identification of unstable areas, trajectories, traces of the previously occurred landslides and five geomechanical stations. The specific weight of eight rock samples in the laboratory of the National University of Huancavelica was also calculated, which served to obtain the weight of the large-scale rock blocks. In addition, the normal and tangential restitution coefficients were calibrated, that is, field trials. Once the data were obtained, modeling was carried out by applying the Rocfall software, whose results of ten trajectories were: final distance reached, bounce height, kinetic energy and translational speed. With these values, risk maps have been prepared, taking into account the areas of housing vulnerability in the city of Huancavelica. Finally, it is proposed to mitigate these risks of rockfall, with dynamic barriers, which is important for the security of housing in the analysis sectors.
\end{abstract}

Key words: Risk prediction, rockfall, trajectory simulation.

\section{Introduction}

The city of Huancavelica is located in the central part of Peru, located on the eastern slope of the Andes mountain range, on the banks of the Ichu River, tributary of the Mantaro River. It has 50,000 inhabitants, located between high mountains called Potocchi mountains, Oropesa mountains, Cruz Pata and Aparinacu mountains and has steep hillside relief, with varying slopes between $41^{\circ}$ and $64^{\circ}$.

Rock block landslides are generally a threat to urban areas located on the slopes of the hills and, according to their degree of risk, can cause losses of materials, economy and in extreme cases of human lives. In addition, there is a lack of interest from local authorities in preventing this type of event, with technological possibilities, which can be of great help

Corresponding author: Iván Ayala Bizarro, master, research field: hydrological and hydraulic modeling to prevent flooding and risk analysis. in response to these types of contingencies.

The latest events caused by rockfalls in the city of Huancavelica, which affected housing in several sectors, is thus the interest of conducting this research called "Analysis and prediction of risks from rockfall in the Huancavelica city".

This research focuses on determining the results of the analysis and prediction of risks due to rockfall, establishing the trajectories for modeling, risk mapping and finally proposing an alternative solution which will be very useful for the field of study.

\section{Material and Methods}

The rocks that fall can reach the foothills in free fall, jumping or rolling [1].

Rocfall is useful in determining mitigation measures where it is possible to analyze the location of elastic and inelastic bars [2]. For the risk analysis of rock shedding [3], they used Rocfall software, including a protection system, to reduce the impact energy of the rocks. 
The houses located at the foot of the hillside of Aparinacu hill, are considered as a critical area, of danger to events due to mass movements. Therefore, it is in imminent danger in the presence of heavy rains - exceptional and seismic events [4].

The fall of rocks is induced by physical and chemical erosion, steep slopes, intense rainfall, earthquakes, among other factors that can cause rock mass collapses.

Rocfall facilitates calculations in rockfalls, for this it is necessary to enter the following parameters: contact profile, initial speed, angular velocity, size and shape of the rock, slope roughness and restitution coefficients (normal and tangential) [5].

\subsection{Analysis of the Movements of Detached Rocks}

To analyze the movements of the rocks that are released, the four modes of movement described below must be considered [6]:

\section{- Freefall}

The movement of a rock's free fall is favorably detailed by the equation of a parabola, where air friction will not be taken into account because it does not significantly influence. The formulas governing the movement of the block are shown below [7]. Table 1 shows the basic equations of the free fall motion.

Fig. 1 shows the analysis of an object in free fall, the parameters and point $\mathrm{P}$ of impact, according to Giani [7].

The point of impact is found at the intersection between the parabola formula and the slope segments. The " $\mathrm{x}$ " and " $\mathrm{y}$ " coordinates at point $\mathrm{P}$ are found as follows:

$$
\begin{gathered}
y=-\frac{1}{2} g \frac{\left(x-x_{0}\right)^{2}}{V_{o x}^{2}}+V_{o y} \frac{\left(x-x_{0}\right)^{2}}{V_{o x}}+y_{0} \\
\frac{y-y_{1}}{y_{2}-y_{1}}=\frac{x-x_{1}}{x_{2}-x_{1}}
\end{gathered}
$$

where:

$\mathrm{V}_{\mathrm{ox}}, \mathrm{y} \mathrm{V}_{\mathrm{oy}}$ : Components of the initial velocity at point $\mathrm{P}_{0}$ (start of displacement and trajectory) on the coordinate axes.
Table 1 Free fall equiattions.

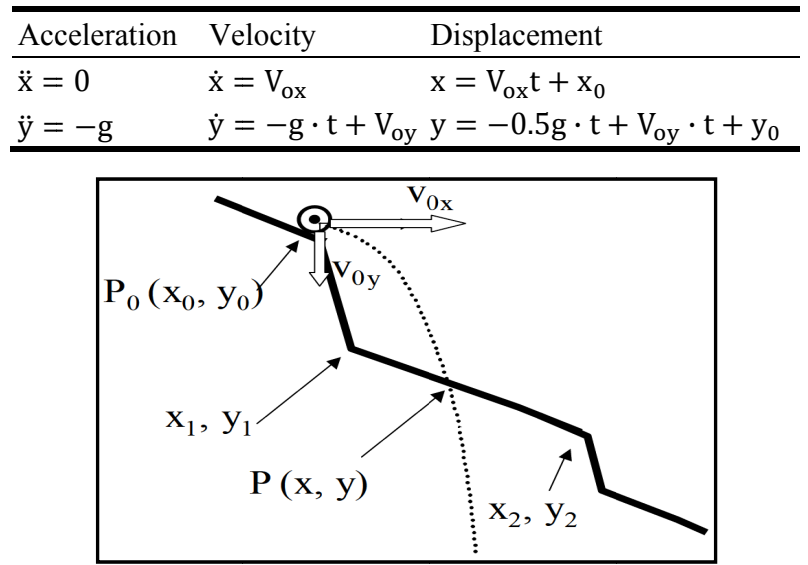

Fig. 1 Free fall path of a block.

$\mathrm{x}_{1}, \mathrm{y}_{1}$ : Coordinates of origin of the segment where the impact occurs.

$\mathrm{x}_{2}, \mathrm{y}_{2}$ : Final coordinates of the aforementioned segment.

$\mathrm{x}_{0}, \mathrm{y}_{0}$ : Start coordinates.

- Bounce:

It is governed by a coefficient of restitution, it also expresses the amount of energy lost in the impact. Generally, the important parameter involved in the phenomenon of rebounding is the restitution coefficient, which is defined by parameters in each of the normal and tangential directions to the rolling surface, as shown in Fig. 2. According to this concept, the normal and tangential restitution coefficients (Rn and $\mathrm{Rt}$ ), are given by:

$$
\mathrm{Rn}=\frac{\mathrm{V}_{\mathrm{nr}}}{\mathrm{V}_{\mathrm{ni}}} \text { y } \mathrm{Rt}=\frac{\mathrm{V}_{\mathrm{tr}}}{\mathrm{V}_{\mathrm{ti}}}
$$

where:

$V_{n r} y V_{n i}$ : They are the normal components of rebound and impact.

$\mathrm{V}_{\mathrm{tr}} \mathrm{y} \mathrm{V}_{\mathrm{ti}}$ : They are the tangential components of rebound and impact.

- Rolling and sliding:

The final speed of a block of rock that rolls or slides in an inclined plane, is obtained using the following equation:

$$
V=\sqrt{2 \cdot g \cdot(\sin \alpha-\operatorname{tg} \theta \cdot \cos \alpha) \cdot l}
$$

where:

$$
g=\text { Acceleration of gravity, }
$$




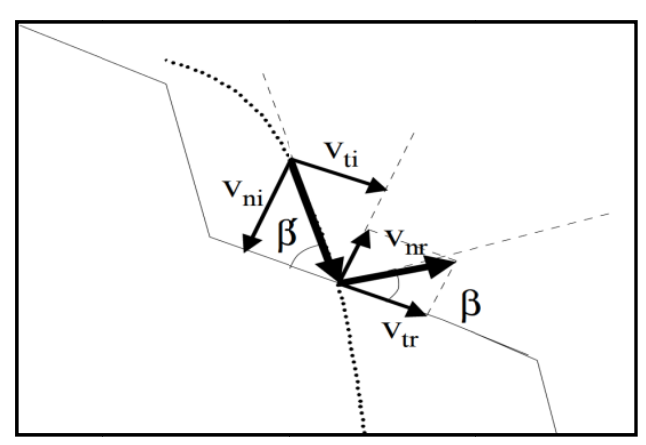

Fig. 2 Free fall path of a block [8].

$\theta=$ The friction angle by rolling or sliding;

$l=$ The segment length and;

$\alpha=$ The angle of inclination of the segment that the rock slides.

In order to analyze the detachment of a rock, the forms that the blocks may have in its path are analyzed: spherical, irregular and regular; as shown in Fig. 3.

\subsection{Theoretical Foundations in the Analysis of Falling Rock Fragments}

According to Warren [10], author of Rocfall software, he states that particle analysis is used to find the path of the rock. There are three distinct parts in this analysis: The particle, projectile and slip algorithms.

\subsubsection{The Particle}

The use of the equation in parametric form is favorable because, the parabolic path of the rock, can intersect multiple slope segments, barriers and the order of intersection must be calculated.

\subsubsection{Projectile Algorithm}

The equations used for projectile calculations are listed below. The parametric equation for a line is:

$$
\begin{gathered}
x=X_{1}+\left(X_{2}-X_{1}\right) u \\
y=y_{1}+\left(y_{2}-y_{1}\right) u \quad u \in[0,1]
\end{gathered}
$$

where:

$X_{1}, Y_{1}$ : It is the first end point of the line.

$X_{2}, Y_{2}$ : It is the second end point of the line.

The parametric equation for a parabola is:

$$
\begin{gathered}
x=V_{\mathrm{X} 0} t+X_{0} \\
y=\frac{1}{2} g t^{2}+V_{\mathrm{Y} 0} t+Y_{0} \quad t \in[0, \infty]
\end{gathered}
$$

where:

$g$ : It is the acceleration of gravity (the sign is negative),

$X_{0}, Y_{0}$ : It is the initial position of the rock,

$V_{\mathrm{X} 0}, V_{\mathrm{Y} 0}$ : It is the initial speed of the rock.

Parametric equations for particle velocity are:

$$
\begin{gathered}
V_{\mathrm{XB}}=V_{\mathrm{X} 0} \\
V_{\mathrm{YB}}=V_{\mathrm{Y} 0}+g t
\end{gathered}
$$

where:

$V_{\mathrm{XB}}, V_{\mathrm{YB}}$ : It is the speed of the rock at any point in the path of the parabolic movement, before the impact.

By matching the points of the parabola and the line equations (that is, $x=x$ and $y=y$ ) and rearranging so:

$$
\begin{aligned}
& \mathrm{a} x^{2}+\mathrm{b} x+\mathrm{c}=0, \text { is obtained: } \\
& \begin{aligned}
{\left[\frac{1}{2} g\right] t^{2}+\left[V_{\mathrm{Y} 0}-q V_{\mathrm{X} 0}\right] \mathrm{t} } \\
+\left[Y_{0}-Y_{1}+q\left(X_{1}-X_{0}\right)\right]=0
\end{aligned}
\end{aligned}
$$

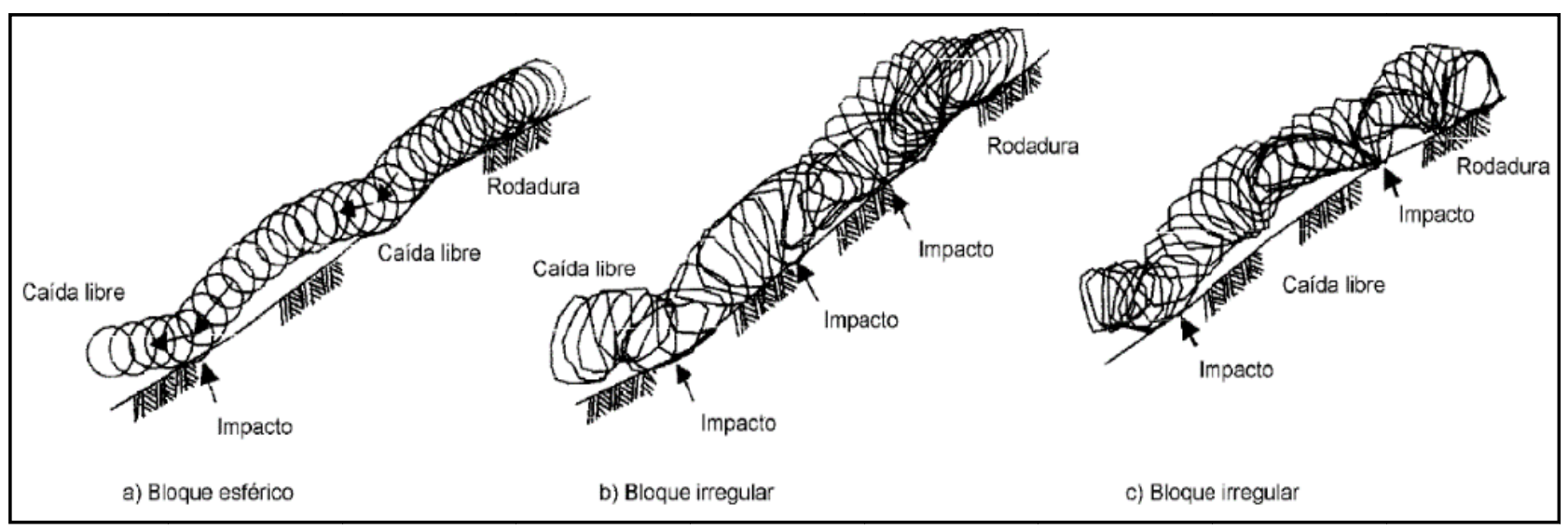

Fig. 3 Movements that a rock can take when it falls off a slope [9]. 
where:

$q$

$=\frac{\left(Y_{2}-Y_{1}\right)}{\left(X_{2}-X_{1}\right)}$ It is the slope of the line segment

Eq. (7) is solved for $t$, using the quadratic equation:

$$
t=\frac{-\mathrm{b} \pm \sqrt{\mathrm{b}^{2}-4 \mathrm{ac}}}{2 \mathrm{a}}
$$

where:

$$
\begin{gathered}
\mathrm{a}=\frac{1}{2} g \\
\mathrm{~b}=V_{\mathrm{Y} 0}-q V_{\mathrm{X} 0} \\
\mathrm{c}=Y_{0}+Y_{1}+q\left(X_{1}-X_{0}\right)
\end{gathered}
$$

At each step through the algorithm, the parabola that is formed by the path of the rock is verified with each segment of the slope and with each barrier. All slope segments and barriers that have a valid intersection with the parabola are entered into a list. The list is cataloged according to the value of the parameter $t$, to find the correct intersection.

Once the proper intersection is found, the velocity before impact is calculated according to Eqs. (5) and (6). These velocities become normal and tangential components to the slope according to:

$$
\begin{aligned}
& V_{\mathrm{NB}}=\left(V_{\mathrm{YB}}\right) \cos (\theta)-\left(V_{\mathrm{XB}}\right) \sin (\theta) \\
& V_{\mathrm{TB}}=\left(V_{\mathrm{YB}}\right) \sin (\theta)-\left(V_{\mathrm{XB}}\right) \cos (\theta)
\end{aligned}
$$

$V_{\mathrm{NB}}, V_{\mathrm{TB}}$ : They are the rock velocity components, before impact, in the normal and tangential directions, respectively, $\theta$ is the slope of the line segment.

The impact is calculated using the refund coefficients, according to:

$$
\begin{aligned}
& V_{\mathrm{NA}}=R_{\mathrm{N}} V_{\mathrm{NB}} \\
& V_{\mathrm{TA}}=R_{\mathrm{T}} V_{\mathrm{TB}}
\end{aligned}
$$

where:

$R_{\mathrm{N}}$ : It is the normal restitution coefficient $\in[0,1]$

$R_{\mathrm{T}}$ : It is the tangential restitution coefficient $\in[0$, 1]

$V_{\mathrm{NA}}, V_{\mathrm{TA}}$ : They are the components of rock velocity, after impact, in the normal and tangential directions, respectively.

Post-impact speeds are transformed back into horizontal and vertical components according to:

$$
\begin{aligned}
& V_{\mathrm{XA}}=\left(V_{\mathrm{NA}}\right) \sin (\theta)+\left(V_{\mathrm{TA}}\right) \cos (\theta) \\
& V_{\mathrm{YA}}=\left(V_{\mathrm{TA}}\right) \sin (\theta)-\left(V_{\mathrm{NA}}\right) \cos (\theta)
\end{aligned}
$$

where:

$V_{\mathrm{XA}}, V_{\mathrm{YA}}$ : They are the components of rock velocity, after impact, on the horizontal and vertical axes, respectively.

Once the correct intersection and velocities have been calculated, the intersection of all data collectors with the parabola is corroborated in a manner analogous to the verification of the slope segments. Any data collector with a parametric value (the value of $t)$ less than the value of the actual intersection is deducted from the rock's path. The location, velocity and kinetic energy of the rock, at the time the data collector passes, are recorded and displayed.

The speed of the rock is found and compared to $V_{\mathrm{MIN}}$. If it is greater than $V_{\mathrm{MIN}}$, the process begins again, with the search for the next intersection point. If the speed is less than that of $V_{\mathrm{MIN}}$, the rock can no longer be considered a particle and is sent to the sliding algorithm.

\subsubsection{Sliding Algorithm}

It is used to calculate the slippage of rocks after they have left the projectile algorithm. The rocks slide in any segment of the slope and barrier. For the purpose of the sliding algorithm, the slope or barrier segment on which the rock slides consist of a single straight-line segment that has slope angle properties $(\Theta)$ and friction angle $(\Phi)$. The friction angle acts as a constant value or sampled from a random distribution.

The rock can begin to move anywhere along the segment and can have an initial velocity that is directed up or down. In the equations only the tangential velocity component to the slope is considered.

Once the movement starts, the algorithm used depends on whether the initial speed is up or down.

\subsubsection{Sliding Downhill}

If the angle of the slope is greater than the angle of friction $(\theta>\Phi)$, the driving force is greater than the resistance force and the rock will slide out of the end 
point of the descending slope with a higher velocity. The speed with which the rock leaves the slope segment is calculated by:

$$
V_{\text {EXIT }}=\sqrt{V_{0}^{2}-2 s g k}
$$

where:

$V_{\text {EXIT: }}$ Speed of the rock at the end of the segment;

$V_{0}$ : Initial speed of the rock, tangential to the segment;

$s$ : Distance from the initial location to the end point of the segment;

$g$ : Acceleration due to gravity $\left(-9.81 \mathrm{~m} / \mathrm{s}^{2}\right)$;

$k: \pm \sin (\theta)-\cos (\theta) \tan (\Phi)$;

where:

$\theta$ : Segment slope;

$\Phi:$ Friction angle of the segment;

\pm : is + if the initial velocity of the rock is descending or zero;

\pm : is - if the initial velocity of the rock is ascending.

If the angle of inclination is less than the angle of friction $(\Theta<\Phi)$, the resistance force is greater than the driving force and the rock will decrease in speed. The rock can stop in the segment, depending on the length of the segment and the initial speed of the rock.

Assuming that the segment is infinitely long, a stopping distance is calculated. The distance is found by adjusting the output speed ( $\left.V_{\text {EXIT }}\right)$ to zero in Eq. (19) and replacing you have:

$$
s=\frac{V_{0}^{2}}{2 g k}
$$

Then the distance from the initial location of the rock to the end of the segment is calculated. If the stop length is greater than the distance at the end of the segment, then the rock will slide out of the end of the segment. In this case, the output speed is calculated using Eq. (19). If the stopping distance is less than the distance at the end of the segment, then the rock will stagnate in the segment and the simulation ends. The location where the rock stops is at a distance of "s" from the initial location.

\subsubsection{Uphill Slide}

When sliding uphill, both the force of friction and the force of gravity decrease the speed of the particle. Assuming that the segment is infinitely long, the particle will eventually stop. The braking distance is calculated using Eq. (20) and the distance from the initial location of the rock to the end of the upward slope of the segment is calculated. If the stopping distance is greater than the distance at the end of the segment, the rock will slide out of the end of the segment. In this case, the output speed is calculated using Eq. (19). If the stopping distance is less than the distance at the end of the segment, the rock stops and the simulation ends.

If the rock slides up and stops, it is inserted into the sliding algorithm on a downward slope. If the segment is inclined enough to allow sliding (i.e., $q>f$ ), the rock will slide along the lower end of the segment. If the segment is not inclined enough, then the location where the rock stopped moving (after sliding uphill) is taken as the final location and the simulation stops.

\subsection{Geomorphology}

The Aparinacu hill is located on the slope of a volcanic mountain and has an average slope of $63.11^{\circ}$, where sedimentary rocks emerge — lutitas and andesitt, highly eroded.

The geomorphological structure is formed by mountains in sedimentary and volcano-sedimentary rocks, with colluvial deposits [4], Fig. 4 shows that the study site belongs to the Chunumayo formation.

\subsection{Geological Hazards of the Area}

In the Ccollpayacu sector belonging to the urban area of the Huancavelica Ascension district, there is a latent danger of detachment of large rock masses for families living on the slopes of the Aparinacu hill, if a rock fall event occurs, it is highly dangerous for these inhabitants and it presents steep slope relief, with variable slopes between $41^{\circ}$ and $64^{\circ}$. 


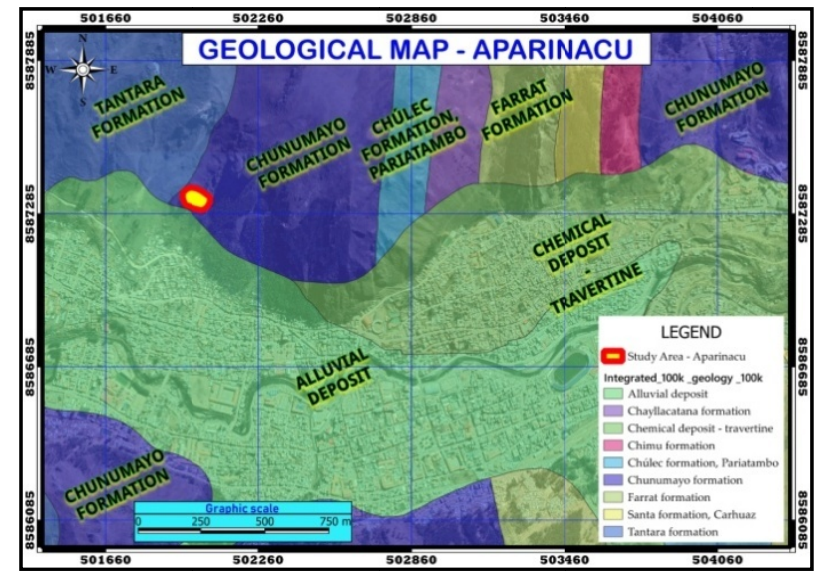

Fig. 4 Geological map, obtained from the GeoCatmin application [8].

To identify the critical areas, several technical field visits were made, with the purpose of identifying potential hazards such as: rockfall and hillside erosion. In addition, it could be evidenced that the potential hazards mentioned above are exposed to homes and families in the urban area.

Gómez and Albinez [4] point out that geological hazards are generated by:

- Very fractured solid rock.

- Meteorization and erosion of limestone outcrops.

- The vertical orientation of the rock mass.

- Poor vegetation cover, downhill.

- Heavy rainfall.

- Seismic events.

In the lower part of the Aparinacu hill a few meters from the urban area, there was evidence of many landslides of rock masses with approximately $4.10 \mathrm{~m}$ in diameter and colluvial deposits, which were raised earlier years as shown in Fig. 5.

In Fig. 6, you can see the aerial photographs taken by the Drone, where the calcareous lithology that protrudes from the Aparinacu hill, is very altered and fractured into seven blocks.

These blocks make a total volume of $11,608.9 \mathrm{~m}^{3}$ (from the photogrammetric analysis), which will be considered in order to perform an analysis of the kinetic energies. It should be noted that thanks to kinetic energy it is possible to draw up a risk map and propose appropriate mitigation alternatives.

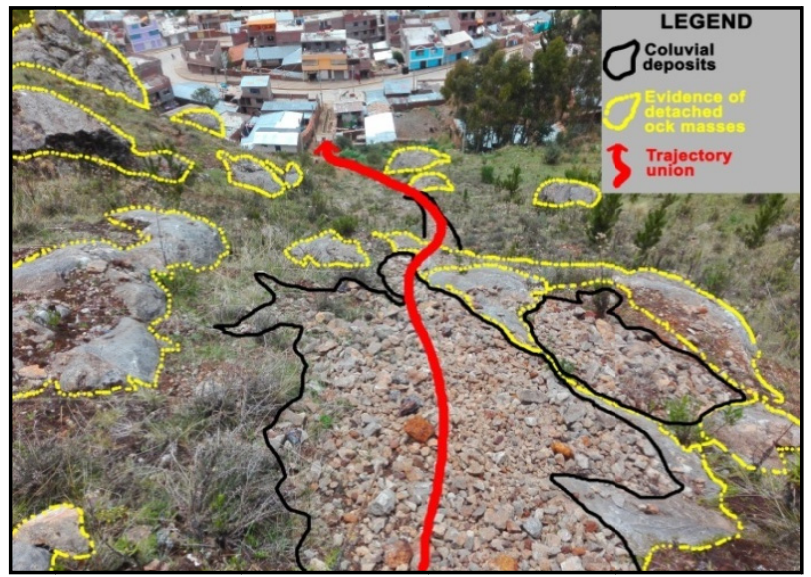

Fig. 5 Evidence of detached rock masses with the presence of colluvial deposits.

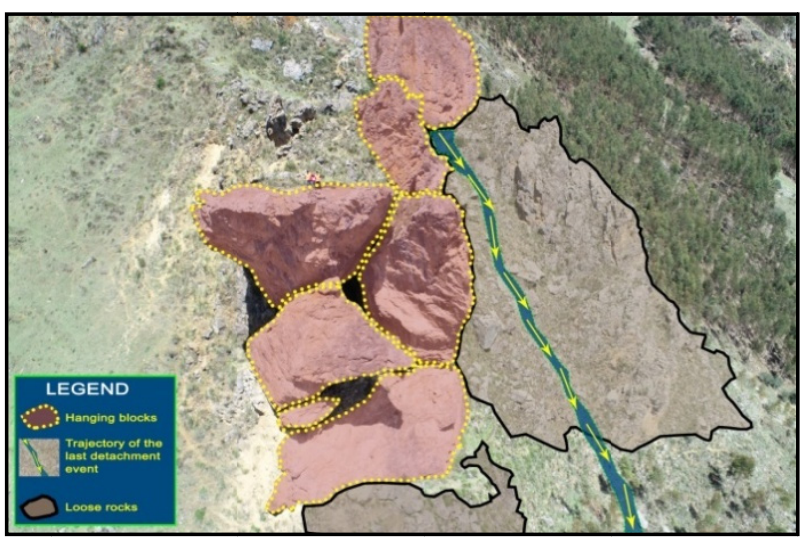

Fig. 6 State of the blocks highly altered and fractured, plus sectors with loose blocks are evident.

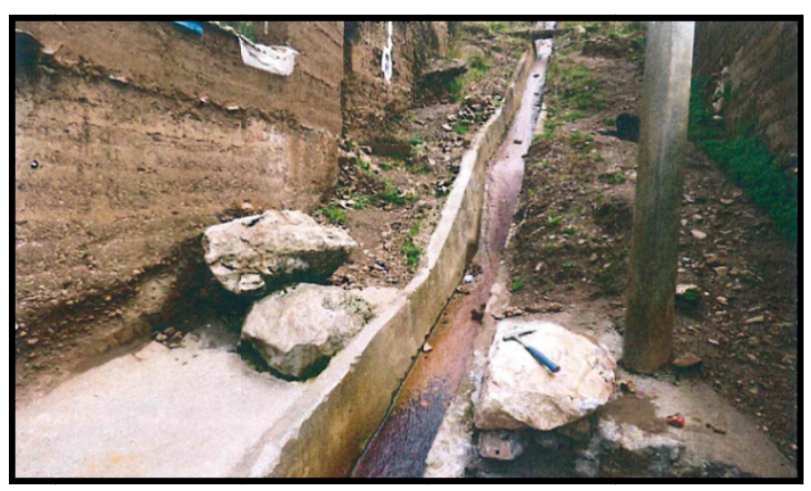

Fig. 7 Fallen rocks with diameters between $0.5 \mathrm{~m}$ and $1.2 \mathrm{~m}$.

On March 28, 2018, a rockfall event arose, due to the intense rainfall, the detachment began on the Aparinacu hill, where according to field visit this hill is weathered, fractured, altered with innumerable loose blocks. Fig. 7 shows some of these that reached the final part of the canal affecting housing in the Ccollpayacu sector. 


\subsection{Rock Path Identification}

The rocks previously detached have a volume of $1,753 \mathrm{~m}^{3}$ for path A, this block is shown in Fig. 8 .

A technical visit to the study area was carried out to determine the possible trajectories of the rocks. Fig. 9 shows these trajectories.

\subsection{Return Value Calibration}

The fall of insitu rocks, with different weights and shapes, was simulated in order to obtain the values of restitution coefficients $(R n, R t)$, for the study area.

To simulate a detachment, the following considerations were taken into account:

The contact profile where the calibration was performed was obtained from the topographic survey mentioned in the previous paragraphs.

The weight of the rocks to be thrown varies according to the Table 2 .

The tests were carried out in the area adjacent to the Aparinacu hill, where it was possible to place in a place of origin for the launch and identify the final paths, take distances, dimensions, weight of the rock fragments.

Fig. 10 shows the test zone, for the calibration of the return values.

The Rocfall software processes all the information collected in the field to determine the return coefficients, also random values of return coefficients were proposed, until obtaining a distance equal to

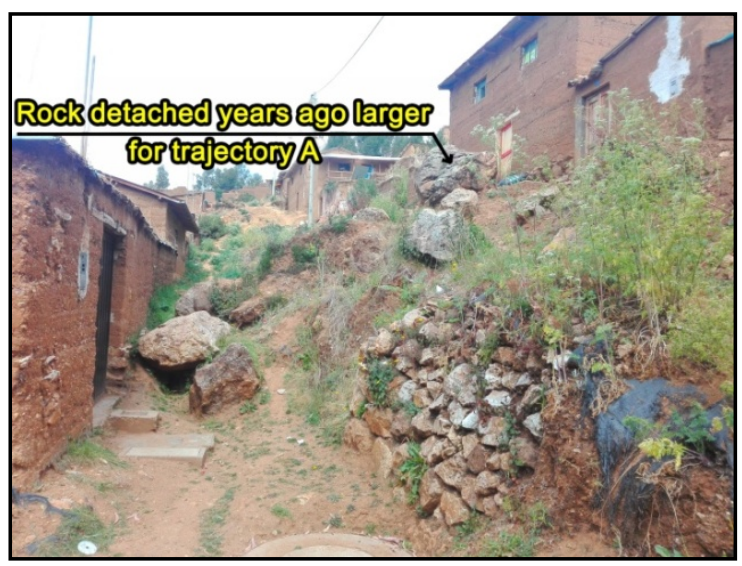

Fig. 8 Rocks detached years ago and settled.

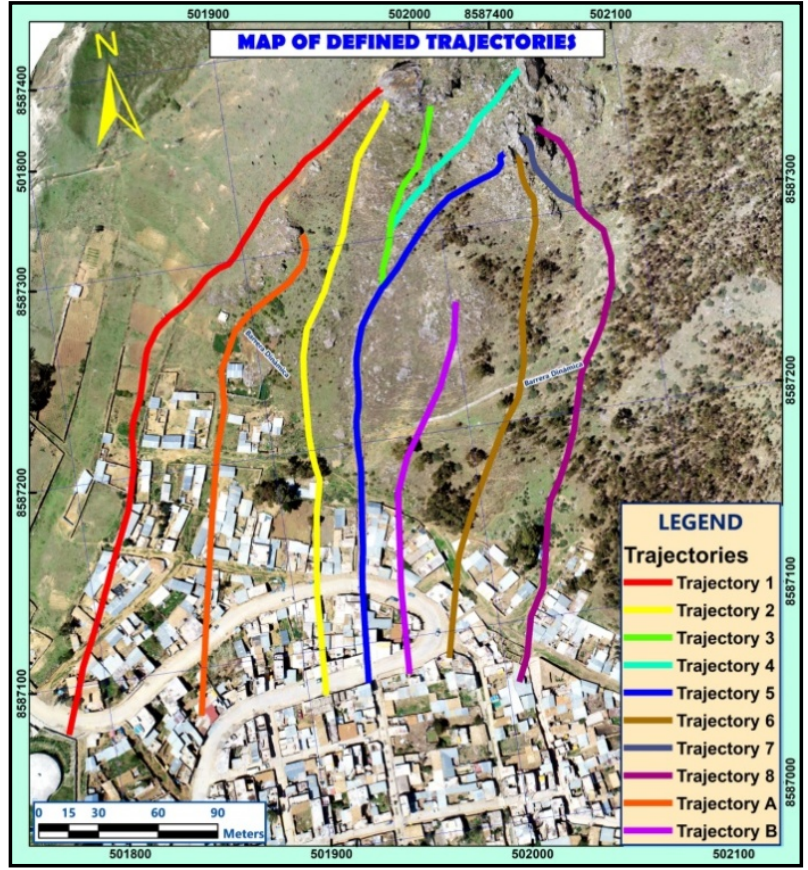

Fig. 9 Defined trajectories for the analysis of possible landslides.

Table 2 Weights of the rocks in the different paths.

\begin{tabular}{ll}
\hline Paths & Thrown mass $(\mathrm{kg})$ \\
\hline 1 & 20.70 \\
2 & 10.85 \\
3 & 9.10 \\
4 & 1.50 \\
5 & 1.10 \\
\hline
\end{tabular}

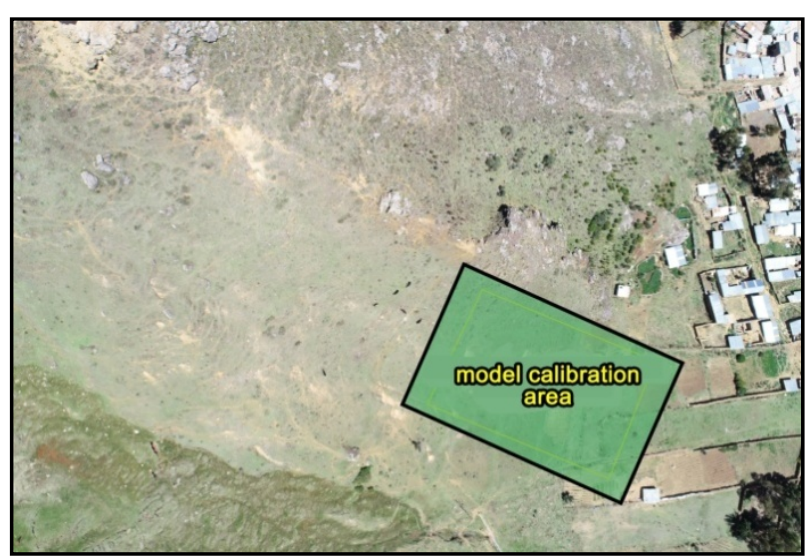

Fig. 10 Calibration zone for restitution coefficients.

those observed in the field, said distance will confirm that the chosen value is adequate, these are shown in Table 3 .

To obtain the normal and tangential restitution coefficient values on a soil surface with little vegetation 
Table 3 Tabulated values of return coefficients.

\begin{tabular}{|c|c|c|c|c|c|c|}
\hline Paths & Thrown mass (kg) & Distance reached $(\mathrm{m})$ & Superficie type & $R n$ & $R t$ & Friction angle $\left({ }^{\circ}\right)$ \\
\hline 1 & 20.7 & 59.422 & Soil with vegetation & 0.300 & 0.774 & 16.730 \\
\hline 2 & 10.85 & 55.985 & Soil with vegetation & 0.320 & 0.802 & 14.145 \\
\hline 3 & 9.1 & 56.273 & Soil with vegetation & 0.320 & 0.848 & 10.270 \\
\hline 4 & 1.5 & 51.595 & Soil with vegetation & 0.310 & 0.765 & 17.600 \\
\hline 5 & 1.1 & 43.558 & Soil with vegetation & 0.330 & 0.724 & 21.885 \\
\hline Mean & & & & 0.32 & 0.78 & 16.13 \\
\hline
\end{tabular}

(as is the case with the calibration zone), an arithmetic average of the five trajectories was performed, which will serve as a reference for this type of surface and its subsequent modeling of the study area. In the case of surfaces other than this one, the values recommended in the "Rocscience restitution coefficient table" and by other authors who conducted similar investigations will be taken into account.

Due to the complexity of obtaining the weight of the rock under study, samples of the eight insitu trajectories of limestone were taken for later testing, based on ASTM C 29 (Volumetric or unit weight of soils). Their respective specific weights were determined whose result is $2,568 \mathrm{~g} / \mathrm{cm}^{3}$. This value was used to determine the mass of rock fragments belonging to the same family.

\subsection{Analysis and Modeling}

In the present study, ten topographic profiles of trajectories identified by geomorphological criteria and events that occurred previously have been modeled. This modeling is done in order to know in detail the final location of the blocks, in case of eventual rockfall.

The coordinates for all paths were extracted from the Digital Elevation Model generated with the AgiSoft PhotoScan Software.

For the modeling, the values obtained from the calibration of the model and the table of Rocscience coefficients were used, which are detailed in Table 4.

\subsubsection{Initial Condition}

The initial speeds on both axes were considered 0.1 $\mathrm{m} / \mathrm{s}$ (to simulate an action of destabilizing motion of the rock at rest).
The weights of the rocks considered in Table 5, are the ones that had the greatest reach and largest, since this is an indicator that rocks of these dimensions fall.

The angular velocity is also considered zero, because the rock or block starts from rest.

For the modeling, a quantity of 50 rocks was used, the minimum stopping speed and the number of horizontal locations for the analysis, will be equal to the total distance in meters of each path.

2.7.2 Rocfall Software Modeling without Dynamic Barrier

The Rocfall software discloses the generally precise and similar predictions seen in the field in obtaining the following maximum distance, bounce height, kinetic energy and speed values. Table 6 shows the results of barrier-free modeling.

According to the modeling carried out in the different paths, the rocks have reaches to the urban area of the Ccollpayacu Sector, with energies of up to $3,863.28 \mathrm{~kJ}$.

2.7.3 Rockfall Software Modeling with Dynamic Barrier

Table 7 shows the summary of the results of the barrier modeling, showing the distances, bounce height, total kinetic energy and velocities of maximum translations.

The barrier prevents the normal detachment of the rocks, in this way the rock stops, but sometimes this does not happen, instead of stopping quickly, the rocks return uphill and again impact the barrier, causing energy to increase; This is the case in the barriers of trajectories 2, 5, 6 and 8 with increases of $5.23 \%, 0.24 \%, 11.61 \%$ and $1.63 \%$ respectively. 
Table 4 Normal and tangential restitution coefficient values.

\begin{tabular}{lllll}
\hline$R n$ & $R t$ & Friction angle $\left(^{\circ}\right)$ & Surface type & Verificaction \\
\hline 0.4 & 0.9 & 10.11 & Outcrop of hard surface rocks, large rocks. & {$[11],[12]$} \\
0.4 & 0.9 & 6.37 & Hard/rigid surface pavement & Calibrated in the study area. \\
0.3 & 0.8 & 16.13 & Soil with little vegetation & {$[11],[12]$} \\
0.4 & 0.9 & 6.37 & Concrete roof & \\
\hline
\end{tabular}

Table 5 Rock volume and weights.

\begin{tabular}{lll}
\hline Paths & Volumen $\left(\mathrm{m}^{3}\right)$ & Weight $(\mathrm{Tn})$ \\
\hline 1 & 3.062 & 7.863 \\
$\mathrm{~A}$ & 1.753 & 4.501 \\
2 & 5.063 & 13.001 \\
3 & 0.234 & 0.601 \\
4 & 0.234 & 0.601 \\
5 & 0.234 & 0.601 \\
$\mathrm{~B}$ & 0.096 & 0.247 \\
6 & 0.034 & 0.088 \\
7 & 2.051 & 5.267 \\
8 & 2.051 & 5.267 \\
\hline
\end{tabular}

Table 6 Results of barrierless modeling.

\begin{tabular}{lllll}
\hline Paths & $\begin{array}{l}\text { Maximum } \\
\text { distance reached }(\mathrm{m})\end{array}$ & $\begin{array}{l}\text { Maximum Bounce height } \\
(\mathrm{m})\end{array}$ & $\begin{array}{l}\text { Maximum total kinetic } \\
\text { energy }(\mathrm{kJ})\end{array}$ & $\begin{array}{l}\text { Maximum translational } \\
\text { speed }(\mathrm{m} / \mathrm{s})\end{array}$ \\
\hline 1 & 317.5 & 1.26 & 839.84 & 13.69 \\
2 & 256.5 & 3.00 & $3,863.28$ & 22.55 \\
3 & 242.5 & 6.61 & 260.04 & 27.36 \\
4 & 2.77 & 270.31 & 26.91 \\
5 & 279.5 & 4.73 & 261.96 & 26.60 \\
6 & 249.5 & 5.82 & 36.64 & 26.98 \\
7 & 223.5 & 6.02 & $2,427.25$ & 28.16 \\
8 & 279.5 & 4.26 & $1,314.79$ & 20.86 \\
A & 279.5 & 1.40 & 272.71 & 10.47 \\
B & 182.5 & 0.49 & 20.47 & 11.31 \\
\hline
\end{tabular}

Table 7 Summary of results of barrier modeling.

\begin{tabular}{lllll}
\hline Paths & $\begin{array}{l}\text { Maximum distance } \\
\text { reached }(\mathrm{m})\end{array}$ & $\begin{array}{l}\text { Maximum bounce } \\
\text { height }(\mathrm{m})\end{array}$ & $\begin{array}{l}\text { Maximum total kinetic } \\
\text { energy }(\mathrm{kJ})\end{array}$ & $\begin{array}{l}\text { Maximum translational } \\
\text { speed }(\mathrm{m} / \mathrm{s})\end{array}$ \\
1 & 144.5 & 0.82 & 750.49 & 12.84 \\
2 & 146.5 & 3.10 & $4,065.41$ & 23.15 \\
3 & 169.5 & 6.17 & 246.70 & 25.35 \\
4 & 207.5 & 2.88 & 269.18 & 27.33 \\
5 & 167.5 & 4.58 & 262.59 & 26.93 \\
6 & 112.5 & 5.85 & 40.90 & 28.35 \\
7 & 127.5 & 4.37 & $2,208.07$ & 26.29 \\
8 & 128.5 & 4.51 & $1,336.24$ & 20.83 \\
$\mathrm{~A}$ & 54.5 & 0.52 & 269.85 & 10.28 \\
$\mathrm{~B}$ & 54.5 & 0.42 & 17.95 & 10.79 \\
\hline
\end{tabular}




\subsection{Mitigation Measures}

The mitigation measures against rockfall that is chosen for this investigation, are the dynamic capacity barriers of 5,000 kJ of absorption energy, according to the maximum energy found in the barrierless modeling that was $3,863.28 \mathrm{~kJ}$, but when model with dynamic barrier the maximum energy is $4,065.41 \mathrm{~kJ}$.

These barriers must be installed in a length of 270 $\mathrm{m}$, distances between posts of 8 to $12 \mathrm{~m}$ and a height of $6 \mathrm{~m}$, this measure was taken into account according to the bounce height which was simulated.

Therefore, the threat posed by rock falls to homes located at the foot of the Aparinacu hill, must be mitigated with the installation of RXE type barriers (these adopt cutting-edge technology with high-strength steel wire networks) or the like.

\subsubsection{Thematic Maps}

As a result, the map of trajectories with threat, map of trajectories with mitigated threat, map of vulnerability, map of risk and map with mitigated risk are shown.

\subsubsection{Block Mapping Map}

The map shown in Fig. 11, shows the amount of rock blocks digitized with photogrammetry techniques, according to the generated histogram, it is observed that there is a greater frequency of blocks between 0 and $10 \mathrm{~kg}$, there is also a large rock (869.31 Tn), in the area of rock outcrop.

In total, 7,566 blocks of rocks were identified, between ranges of 0.001 and $338.52 \mathrm{~m}^{3}$ except for rocks that could not be identified, being smaller.

\subsubsection{Threat Trajectory Map}

Fig. 12 shows that the red paths show the areas with the greatest energy originated during a possible detachment, which is why these areas are considered to be the greatest threat to homes adjacent to the Aparinacu hill. In the case of the paths that stand out in blue, they can be considered areas of least threat or in their absence.

\subsubsection{Path Map with Mitigated Threat}

Once the modeling was performed, the location of the dynamic barrier was identified as shown in Fig. 13 (green color: areas with mitigated trajectories; red color: areas with high threat).

\subsubsection{Vulnerability Map}

These areas are vulnerable to rock falls, due to the location of the houses themselves, so it is classified in

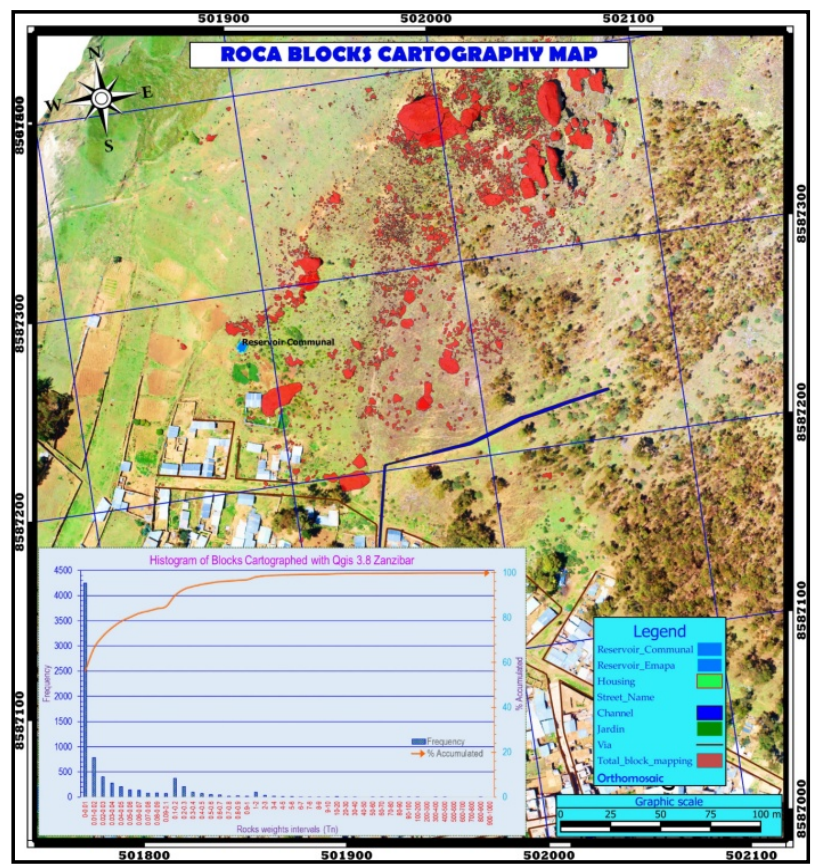

Fig. 11 Block mapping map.

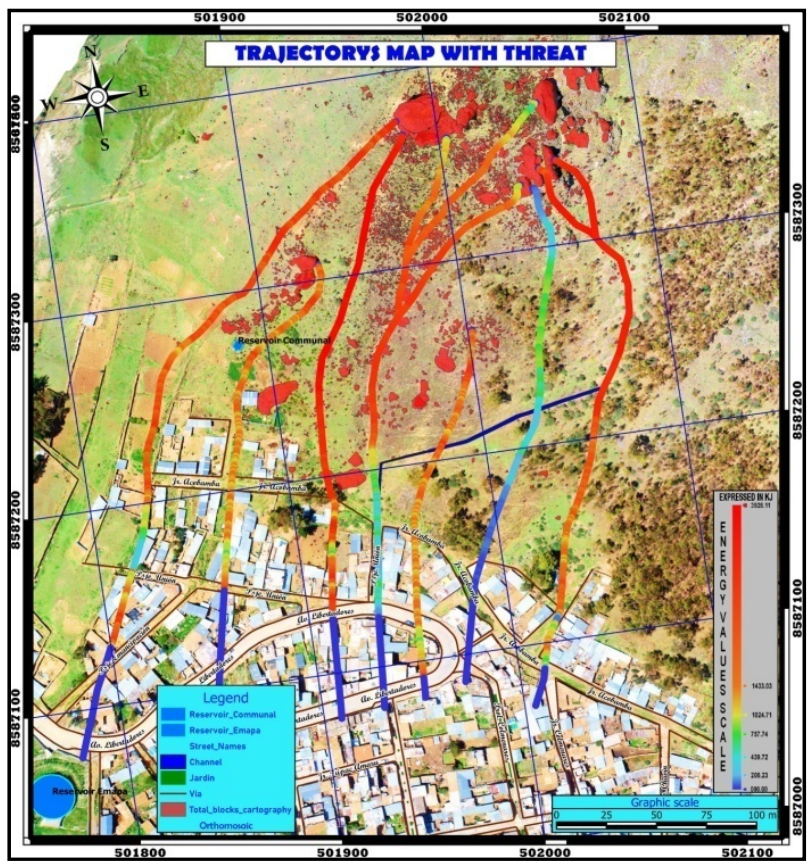

Fig. 12 Threat trajectory map. 


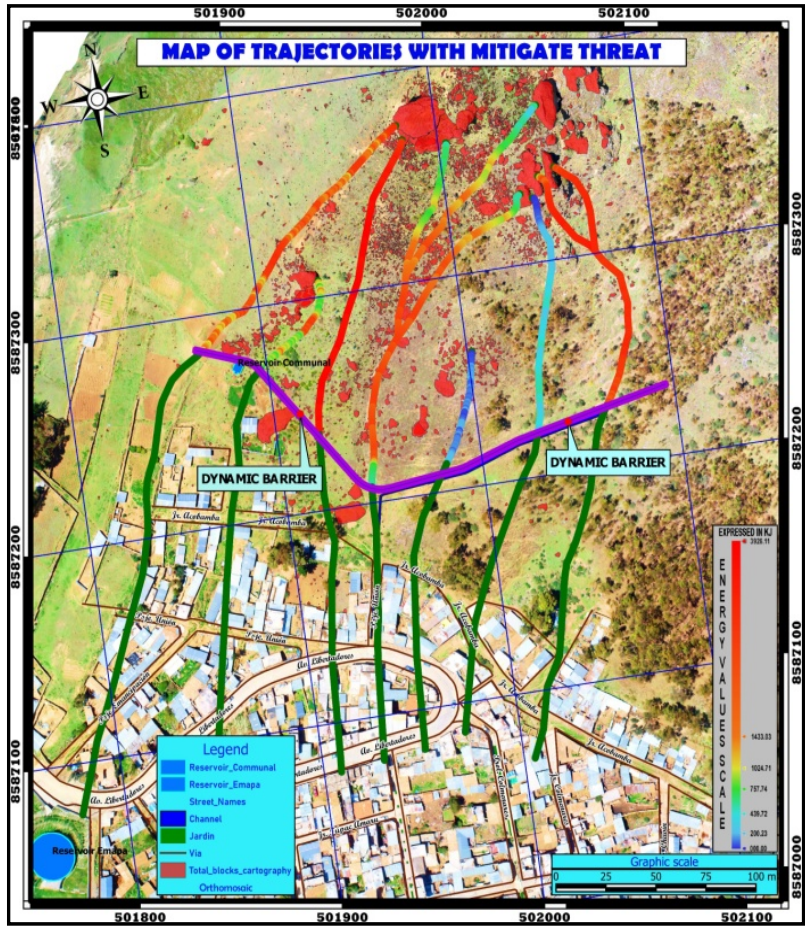

Fig. 13 Path map with mitigated threat.

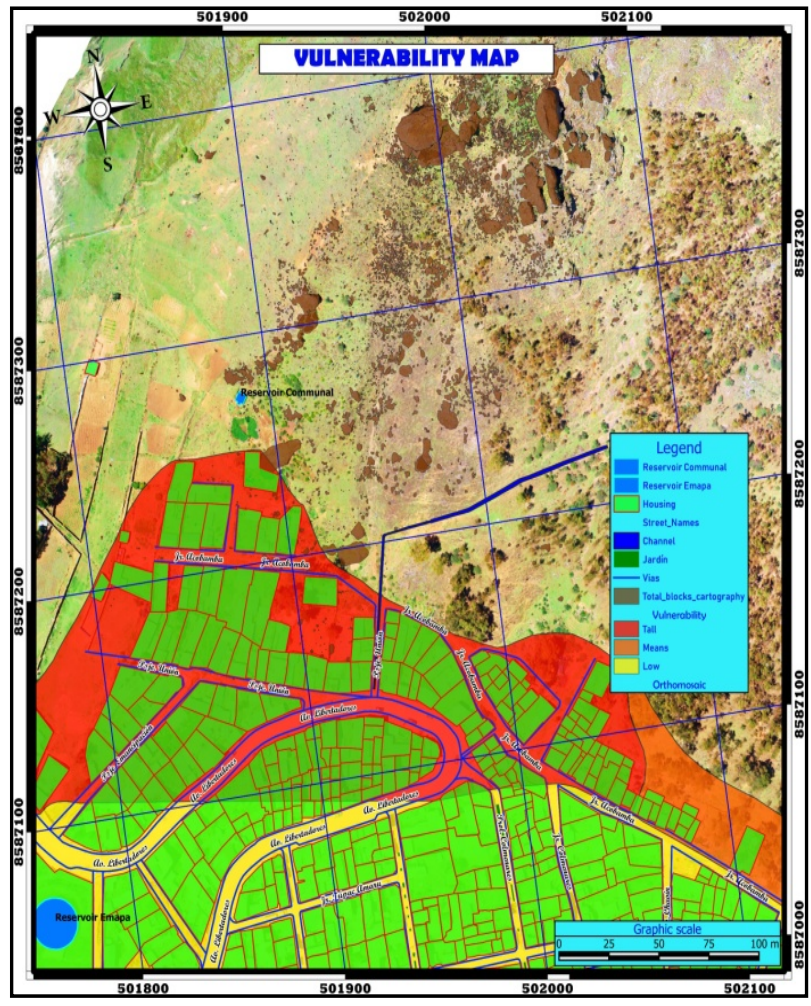

Fig. 14 Vulnerability map of the study area.

areas of high vulnerability with 146 homes, average with 13 homes and low with 253 homes, which is shown in Fig. 14.

\subsubsection{Risk map of the study area}

The very high risk represents the central part of the map (red color) which includes free areas and 98 homes to be affected before a possible detachment, it is clarified that to identify the risk the threat (energy) and vulnerability (housing) were taken into account.

The risk scores shown in Fig. 15 include: 0.00 zones with very low risk (dark green color), 0.25 with low risk (light green color), 0.50 with medium risk (yellow color), 0.75 with high risk (color orange) and finally a score of 1.00 with very high risk.

2.8.7 Map with Mitigated Risk: Solutions with Dynamic Barriers

Once the thematic map of risks was obtained, it was analyzed to install some alternative solution to this type of risks and thus be able to mitigate. Dynamic barriers are proposed, due to their high degree of elastic support and dissipation against kinetic energies in motion.

The areas located below the barrier shown in Fig. 16 (blue strip), are safer areas in the event of a rockfall event.

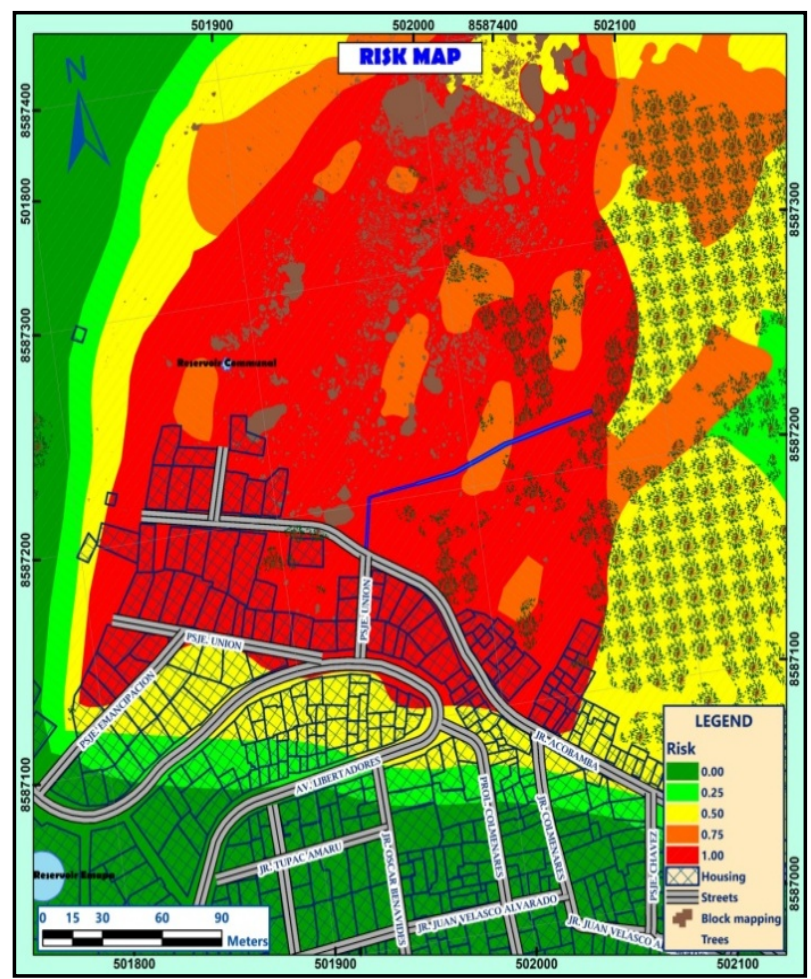

Fig. 15 Risk map of the study area. 


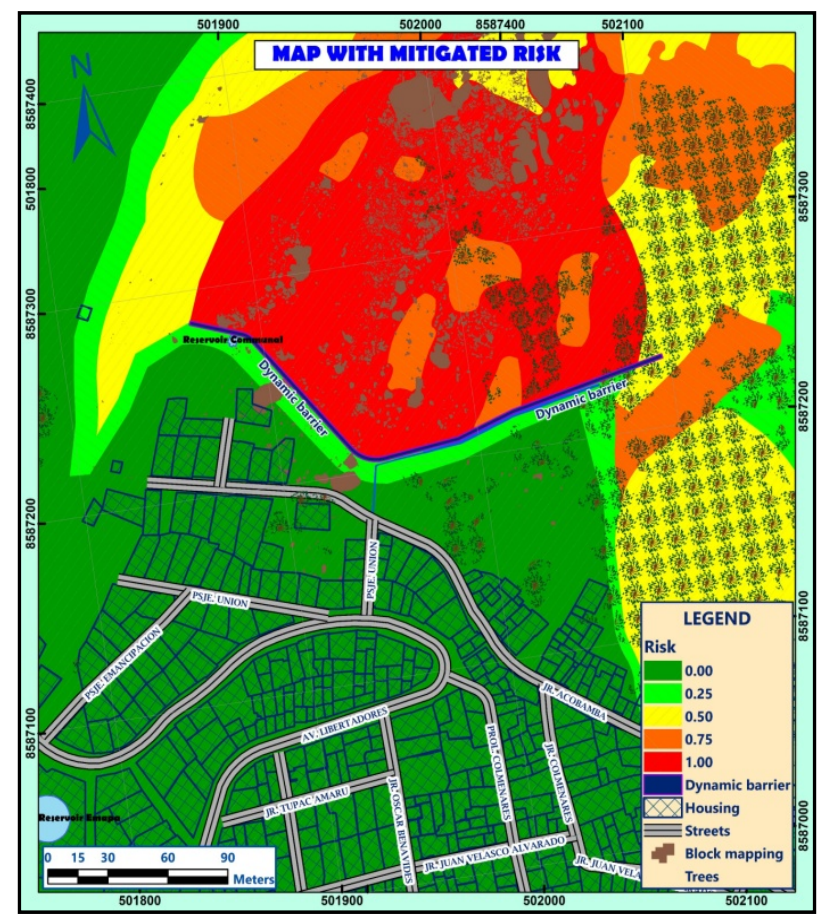

Fig. 16 Map with mitigated risk.

\section{Conclusions}

The validation of coefficients of restitution for a rolling surface of soil with vegetation, became insitu, obtaining normal restitution values of 0.32 and tangential restitution of 0.78 , these results were taken as the basis, to accept the values suggested by several authors, to other surfaces such as: rocky outcrop, rigid pavement and concrete roof.

The modeling in the Rocfall software allows the analysis of rock detachment with static or dynamic barrier, as well as an analysis without barriers. When modeling without the barrier, the following parameters are determined: maximum range distance of $317.5 \mathrm{~m}$ in path 1 from the location of the rock outcrop, maximum rebound height of $6.61 \mathrm{~m}$ in path 3 , maximum energy of $3,863.28 \mathrm{~kJ}$ in trajectory 2 and translational speed of $28.16 \mathrm{~m} / \mathrm{s}$ on trajectory 7 . With these results obtained, the capacity of the barrier to be installed (RXE 5000 system) and the height that it will have $(6.00 \mathrm{~m})$ over a length of $270 \mathrm{~m}$ were chosen, in order to mitigate the threat of falling rocks.

When performing the analysis and predicting the risk of rockfall, based on the slope of the study area, the energies during modeling and the areas of the homes located on the slopes of the Aparinacu hill, thematic maps are prepared showing the risks without the dynamic barrier and then including the dynamic barrier in a length of $270 \mathrm{~m}$, resulting in the houses to be affected during an eventual rockfall which are: 98 homes with very high risk level, 92 homes with medium risk and 52 homes with risk low.

It is proposed to install dynamic barriers since they are better suited to the topography of the area and absorb high energies from rock falls of up to 10,000 $\mathrm{kJ}$ according to Geobrugg [13], unlike the static barriers that support a maximum energy of $70 \mathrm{~kJ}$, according to García [5], if dynamic barriers are not installed, housing must be relocated, due to the high risk of the study area.

\section{References}

[1] Valerio, L. 2012. "Barreras dinámicas a base de materiales convencionales para el control de caídas de rocas." Tesis de pregrado, Universidad Nacional Autónoma de México. (in Spanish)

[2] Escamilla, F. 2014. "Caída de fragmentos de roca y metodología para una adecuada modelación." MSc tesis, Universidad Nacional Autónoma de México. (in Spanish)

[3] Almandalawi, M., You, D., Dowling, K., and Sabry, M. 2015. "Slope Stability and Rockfall Hazard Analysis in Open Pit Zinc Mine.” Int. J. GEOMATE 8 (1): 1143-50..

[4] Gómez, D., and Albinez, L. 2018. "Caída de rocas del cerro Aparinacu, Sector La Quinta Boliviana, distrito Ascensión, provincia y departamento Huancavelica." Informe Técnico No. A6854, Ingenmet. Obtenido de http://sigrid.cenepred.gob.pe/sigridv3/documento/6095. (in Spanish)

[5] García, F. 2005. “Análisis y Diseño de estabilidad sísmica de taludes en suelos y rocas-caso curvas La Leona." Tesis de Pregrado, Universidad Nacional de Ingeniería Civil. (in Spanish)

[6] Ramírez, P., and Alejano, L. 2004. Mecánica de Rocas: Fundamentos e ingeniería de taludes. (in Spanish)

[7] Giani, G. 1992. Rock Slope Stability Analysis, edited by Balkema, 191-208. Obtenido de https://www.researchgate.net/publication/37408018.

[8] Ingemmet. 2019. Geocatmin. Obtenido de http://geocatmin.ingemmet.gob.pe/geocatmin/.

[9] Ministerio de Fomento. 1996. Protección contra desprendimientos de rocas: Pantallas dinámicas. 
Gobierno de España, Dirección General de Carreteras. España: Centro de publicaciones-Secretaria General Técnica. Obtenido de https://www.fomento. gob.es/recursos_mfom/0710600_1.pdf. (in Spanish)

[10] Warren, S. 1998. "Rocfall: A Tool for Probabilistic Analysis, Design of Remedial Measures and Prediction of Rock Falls." MSc thesis, Universidad de Toronto.

[11] Pfeiffer, T., and Bowen, T. 1989. "Computer Simulation of Rock Jumps." Boletín de la Asociación de Geólogos de
Ingeniería 26 (1): 135-46.

[12] Rocscience. 2003. "Advanced Tutorial." RocNews. Obtenido de https://rocscience.com/documents/pdfs/uploads/7741.pdf.

[13] Geobrugg. 2019. "Safety Is Our Nature." Recuperado el 5 de octubre de 2019, de https://www. geobrugg.com/datei.php?src=portal/downloadcenter/datei en/downloadcenter/level1-brochures/RXE-barrier/L1_Ro ckfall-RXE_brochure_screen_180730-ES.pdf 